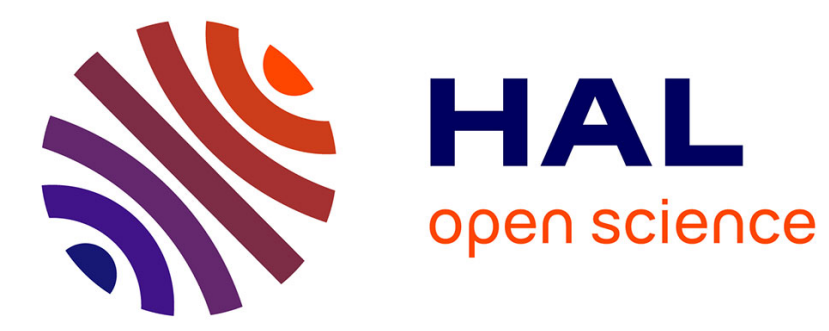

\title{
Resilience activation in extreme situations: a literature review
}

\author{
Cécile Geoffroy, Eric Rigaud, Franck Guarnieri
}

\section{To cite this version:}

Cécile Geoffroy, Eric Rigaud, Franck Guarnieri. Resilience activation in extreme situations: a literature review. ESREL 2016, Sep 2016, Glasgow, United Kingdom. pp.2231-2237 - ISBN 978-1-138-02997-2. hal-01377033

\section{HAL Id: hal-01377033 \\ https://hal-mines-paristech.archives-ouvertes.fr/hal-01377033}

Submitted on 6 Oct 2016

HAL is a multi-disciplinary open access archive for the deposit and dissemination of scientific research documents, whether they are published or not. The documents may come from teaching and research institutions in France or abroad, or from public or private research centers.
L'archive ouverte pluridisciplinaire HAL, est destinée au dépôt et à la diffusion de documents scientifiques de niveau recherche, publiés ou non, émanant des établissements d'enseignement et de recherche français ou étrangers, des laboratoires publics ou privés. 


\title{
Resilience activation in extreme situations: a literature review
}

\author{
C. GEOFFROY, E. RIGAUD, F. GUARNIERI \\ MINES ParisTech, PSL Research University, CRC, \\ Centre de recherche sur les Risques et les Crises, \\ CS 10207 rue Claude Daunesse 06904 Sophia Antipolis Cedex, France
}

\begin{abstract}
This paper makes a scientific contribution to the theme of human and organisational factors in extreme situations in the context of the nuclear industry. The concept of resilience activation in an extreme situation is defined and illustrated, and the initial temporal phase is discussed. The Fukushima Dai Ichi nuclear power plant accident is used as a case study to support the definition and illustrate the concept.
\end{abstract}

\section{INTRODUCTION}

The concept of resilience is gaining in popularity (Bhamra et al. 2011), particularly given the increasing number of situations in which people have to take decisions and act in conditions where there is a high level of uncertainty, danger and public pressure (Guarnieri et al. 2015). Numerous changes mean that societies are becoming more complex and interconnected, while in the safety sciences, resilience studies have emerged that increase our understanding of how individuals, groups and organisations respond and recover from exceptional, extreme and chaotic situations. Nevertheless, there is both a lack of consensus on the definition of resilience, and a lack of empirical studies and practical solutions.

Resilience is associated with the successful adaptations of a system to an event. Theories and models address, among other mechanisms, prevention, response and recovery phases. Resilience activation focuses on the early stages of the response phase in order to understand adaptive capacities (Dalziell and McManus 2004) and any contingent factors that positively or negatively influence their efficiency. This phase includes the initial shock (when people have to face the event), the process of overcoming this shock, and any initial actions that bring the situation under control - or not (understanding the situation, the decision to act, deciding what behaviour to adopt, mobilisation of resources, etc.).

The article is structured into two parts. The first presents the theoretical context of the study, and in particular the notion of resilience and its use in the field of the safety management. Secondly, the notion of resilience activation is discussed through the study of various models of resilience. In this section, the concept of resilience activation is applied to a case study of the events at the Fukushima Dai Ichi power plant.

\section{RESILIENCE ACTIVATION IN EXTREME SITUATIONS}

Extreme means "beyond the normal range of human experience" (Boyden and Mann 2005). The extreme situation threatens the status quo as it is consistent with unusual, invisible and even inconceivable events. The expression extreme situation has at least three characteristics: confronting the unthinkable or the unpresentable; a change or upheaval in values or standards that served as reference points or limits, leading to a serious and more-or-less sudden attack on the person's somatic, mental and/ or symbolic integrity that affects the relationship to oneself, others and/ or the environment; and the implementation of diverse resilience strategies that can appear paradoxical, and which are aimed not just at survival, but particularly mental survival.

In an extreme situation, the surprise caused by rapidly-changing conditions or circumstances leads to stupor and shock caused by the incoherence between the subject who must take action and their environment (Guarnieri et al. 2015). The extreme situation distorts standards and social values and leads to the loss of the usual points of reference. Individuals feel powerless, anxious and fearful in the face of an unprecedented, violent 
event that may be life-threatening (Travadel and Guarnieri 2015). Such situations shatter existing value systems and a new system must emerge. Subjects in an extreme situation are torn between the public pressure to act, and the physical impossibility of taking action within the established framework. The Fukushima Dai Ichi accident demonstrates how difficult it can be for an organisation to activate resilience; in other words, to manage the consequences of an accident in order to increase the likelihood that the situation will be brought fully under control (Guarnieri and Travadel 2014).

The following section characterises the challenges linked to resilience for a system in an extreme situation.

\subsection{The concept of resilience}

The concept of resilience refers to the capacity of an individual, a community of individuals, an organisation, a region, or a sociotechnical system to react to a shock, in order to maintain or restore the essential functions of the system and adapt itself to environmental transformations.

The following definitions are drawn from Guarnieri et al. (2016). Etymologically the term 'resilience' comes from the Latin, re and salire (rise). It indicates a retroactive effect (Plodinec 2013). In ecology, in the $1970 \mathrm{~s}$, the term referred to the capacity to absorb and overcome the effects of a large-scale, unforeseen and brutal ecological disturbance (Holling 1973). Since then, definitions have become more hybrid and multidisciplinary, and the concept is found in geography (Adger 2000), psychology (Richardson 2002), including popular psychology (Cyrulnik and Seron 2003) sociology (Saint-Arnaud and Bernard 2003), organisational sciences (Baardwijk and Reinmoeller 2005) or ergo-psychology (Hollnagel, Woods, and Leveson 2006). It can be defined as the capacity of a system to absorb disturbances and reorganise itself during continuous change (Walker et al. 2004).

To illustrate the diversity of uses of the notion of resilience, the following table (Table 1) presents a set of definitions found in various scientific contexts. These references were selected as they are frequently quoted in studies of resilience, in syntheses of existing definitions, or because of the status of the body that provided it (e.g. the United Nations).

Table 1. Selected definitions of resilience

\section{Definition}

The persistence of relationships within a system; a measure of the ability of systems to absorb changes of state variables, driving variables, and parameters, and still persist (Holling 1973)

The capacity to cope with unanticipated dangers after they have become manifest, learning to bounce back (Wildavsky 1991)

The capacity to adapt existing resources and skills to new systems and operating conditions (Comfort 1999)

The ability to withstand an extreme event without suffering devastating losses, damage, diminished productivity, or quality of life without a large amount of assistance from outside the community (Mileti 1999)

The capability to bounce back and to use physical and economic resources effectively to aid recovery following exposure to hazards (Paton et al. 2001)

The ability to recognize and adapt to handle unanticipated perturbations that call into question the model of competence, and demand a shift of processes, strategies and coordination (Woods 2006)

The ability of a system, community or society exposed to hazards to resist, absorb, accommodate to and recover from the effects of a hazard in a timely and efficient manner, including through the preservation and restoration of its essential basic structures and functions (UNISDR 2009)

The intrinsic ability of a system to adjust its functioning prior to, during, or following changes and disturbances, so that it can sustain required operations under both expected and unexpected situations (Hollnagel et al. 2010)

A bibliographical approach led to the identification of several models designed to describe the various states and phases of a system that faces a crisis situation. A set of keywords related to resilience provided the starting point for a Scopus, Web of Science, and Google Scholar search, which resulted in seven models that structured our study. 


\subsection{A survey of resilience models}

The survey of resilience models aimed to characterise the phase of resilience activation. The seven models were identified by a review of scientific journals and books on the topics of crisis, disaster and resilience management. The seven models are shown in Table 2, and they describe processes independently of the system they are related to (the individual, organisation, region, etc.).

Table 2. Selected models of resilience

\section{Models}

General Adaptation Syndrome (Selye 1955 )

Panarchy (Gunderson and Holling 2002)

Stress Resistance and Resilience Over Time (Norris et al. 2008)

Disaster Resilience of Place (Cutter et al. 2008)

Resilience Activation (Powley 2009)

Resilience Analysis Grid (Hollnagel et al. 2010)

3D model (Béné et al. 2012)

The General Adaptation Syndrome (Selye 1955) aims to formalize the various biological phases that structure the behaviour of individuals facing a stressful event. Four phases are distinguished: 1) alarm, which occurs at the time of the event; 2) resistance, which occurs if the stressful event goes on for more than 48 hours; 3) return to calm; and 4) exhaustion, which results from chronic stress that compromises the immune system, and leads to hormonal changes and psychosomatic diseases.

The dynamics of socio-ecological systems, or Panarchy model (Gunderson and Holling 2002) considers transitions and transformations in states and the thresholds for transitions in systems. Each state corresponds to a balance between social and ecological subsystems. The transition from one state to another occurs when a set of key stability thresholds are exceeded. The change of state is generally irreversible and engenders a transformation in the structure and dynamics of the system. These changes can have unexpected and unwanted consequences. The adaptive dynamics of a socio-ecological system are seen in terms of a four-phase cycle: 1) growth; 2) preservation; 3) liberation; and 4) reorganisation.

The Resistance to Stress and Resilience Over Time model (Norris et al. 2008) considers four interconnected elements: 1) crisis situations caused by an interaction between a stressor, or adversity that threatens the well-being or functioning of a system on the one hand and, on the other hand, the resources and capacities of a system; 2) resistance corresponds to situations where resources and capacities can negate the stressor before dysfunction occurs; 3) dysfunction corresponds to situations where the stressor exceeds the resources of the system; and 4) resilience leads to a return to functioning in the environment through the mobilisation of resources.

The DROP model (Disaster Resilience of Place) (Cutter et al. 2008) considers the process of resilience in terms of a model composed of five interconnected components: 1) the initial (social) system, a constructed environment and a natural system that are described using the concepts of inherent vulnerability and resilience; 2) a dangerous event characterised by its frequency, duration, intensity, scale and speed of appearance; 3 ) the immediate impact of the event on the system, which is limited or amplified by the presence or absence of prevention and response mechanisms; 4) whether the capacity to absorb the consequences of the event may be exceeded, depending on the nature of the event or the efficiency of system response mechanisms; and 5) the extent of recovery, the knowledge gained and the extent of positive or negative change in the initial system.

The Resilience Activation model (Powley 2009) considers that three key moments are necessary for an organisation to overcome a trauma: 1) liminal suspension aims to restore the psychological, emotional and relational balance of all of the actors in the system; 2) compassionate witnessing aims to restore social order; and 3) relational redundancy aims to restore the balance between the organisation and its environment.

The Resilience Analysis Grid (Hollnagel et al. 2010) considers four key capacities: 1) the capacity to face a diversity of potential undesirable situations; 2) the capacity to oversee the functioning of the system and its evolution; 3 ) the capacity to anticipate the positive and negative consequences of changes and the evolution of the system; and 4) the capacity to learn positive and negative lessons from past situations.

The 3D model (Béné et al. 2012) considers resilience to a shock as an emergent property resulting from three capacities: absorption, adaptation and transformation. If the shock is small, the system will be able to resist and absorb its impact without any consequences. If the absorption capacity is exceeded, adaptation capaci- 
ty is mobilised and adjustments are made that allow the system to continue to work without any qualitative changes to its functions or structural identity. If the shock exceeds the system's adaptation capacity, changes become transformation, with consequences for the primary structure of the system and its main functions.

\subsection{Resilience activation}

A disaster can be described as the passage from a routine situation to an unusual situation that the system is designed for, or an exceptional situation that the system is not designed for. The exceptional situation ends when a new routine emerges (Stallings 2006). Resilience activation studies the phenomena that occur immediately following the transition from the routine situation to the exceptional situation, which structure the response and recovery phases of the system.

The Powley model was selected as the framework for the analysis as it takes into account the dynamic dimension of resilience; it makes it possible to study how strength emerges after a trauma and helps to understand the mobilisation of resources (Guarnieri et al. 2016).

Resilience activation (Powley 2009) and organisational healing (Powley 2013; Powley and Cameron 2008; Powley and Powley 2012) models help to identify the initial stages of the general process of resilience and define the key steps that help an organisation to overcome a trauma. The concept of the critical period is used to describe the moment when the system, disrupted by a shock, first introduces a set of actions designed to restore stability. These interdependent phases and mechanisms structure resilience activation and organisational healing. In this paper, we link these phases and mechanisms in order to simplify the description of the model.

Protective inflammation marks the phase where relational structures are altered, and new relational patterns emerge. The suspension of relational structures encourages new and different interactions among the organisation's members and offer opportunities to support others and connect in ways that go beyond functional and organisational boundaries. The organisation's members have time to readjust psychologically, emotionally and relationally. The unwanted event leads to the suspension of routine activities and resources are allocated to overcoming the consequences of the event and preventing the escalation of the situation;

Compassionate witnessing involves acknowledging and feeling empathy for others. A temporary equality emerges between the organisation's members, which structures a space where they are on an equal footing. They are able to show compassion and act in ways that foster caring and supportive relationships.

Relational redundancy refers to how interpersonal connections interact and extend beyond the immediate social reference groups. Individuals find ways to connect with other people, some of whom are not part of their usual circle. This higher level of interaction demonstrates how resilience is activated, specifically through the multiple actions taken by the organisation's members who share critical information, connect with others, and expand their network of influence. This layer makes it possible to gradually rebuild an operational social network, consisting of the new routines, tasks and processes that are necessary for the functioning of the system in the new organisational context;

Remodelling refers to the period when a new organisational structure is gradually put in place. A process of learning strengthens the organisation, which becomes sensitive to new, unexpected events and prepares to protect itself in order to mitigate the consequences. It is also a phase for celebrating the success of the crisis management process and strengthening the social relationships that emerged during the crisis.

These phases are supported by four key mechanisms. First, empathy fosters a sensitive response at the beginning of the process and strengthens relationships. Second, internal or external interventions help in facing fear and intimidation, stimulate social processes, and allow growth and reconstruction. Third, collective efforts reflects the strong feeling of identification of actors in the system with the organisation and its mission, which helps in the resumption and strengthening of social and organisational processes. Finally, leadership helps to structure and maintain cohesion between the various actors in the system.

This first section characterised the concept of resilience activation and the extreme situation. The next section illustrates these concepts and outlines avenues for future research.

\section{APPLICATION TO THE FUKUSHIMA DAI ICHI NUCLEAR POWER PLANT ACCIDENT}

This section presents the results of an initial analysis of the testimony of Masao Yoshida, the Director of the Fukushima Dai Ichi nuclear power plant (Guarnieri et al. 2015). It begins with a summary of the facts, then goes on to present the key avenues of research based on resilience activation studies. Finally, an initial application is described. 


\subsection{The analytical framework}

The resilience activation model is structured into three phases. The first relates to the restoration of the physiological and psychological balance of the actors in the system. The second concerns the restoration of the social order within the system. Finally, the third outlines the restoration of the balance between the organisation and its environment. For each of these three phases, an analysis framework, derived from the various models presented by Powley is applied.

The schema showed below summarises the framework.

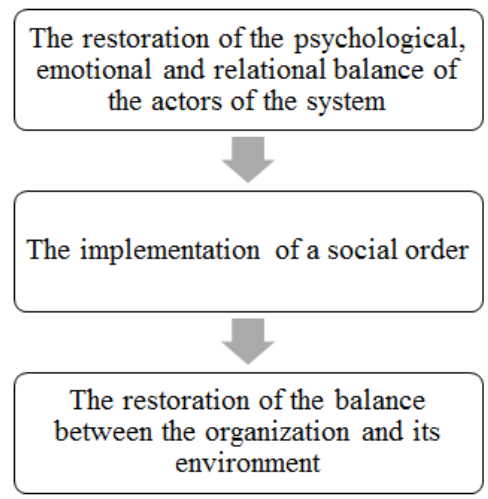

Figure 1. The analytical framework for resilience activation.

\subsubsection{Phase 1: The restoration of the psychological, emotional and relational balance of actors in the system}

The first phase is characterised by four criteria:

- Collapse of points of reference, relations and routine activities following an event;

- Recovery is a temporary period dedicated to physiological, emotional and relational healing;

- Diagnosis of the needs of individuals. This criterion concerns an assessment of the psychological, physiological and emotional state of agents;

- Emergence of a social order reflecting the resilience of individuals. This criterion concerns the organised or spontaneous implementation of interactions to support the recovery of agents.

\subsubsection{Phase 2: Restoration of a social order}

The second phase is characterised by three criteria:

- Exchange is dedicated to the sharing of experiences. This criterion concerns interactions between agents and the sharing of experiences relative to the shock;

- Caution and adaptation: interactions between individuals are cautious and adapted to the emotional, physical and social needs of interlocutors;

- Creation: the system fosters the creation of solid links between individuals.

\subsubsection{Phase 3: Restoration of the balance between the organisation and its environment}

The third phase is characterised by four criteria:

- Increase: the social order increases due to the increase of connections and information exchange between actors;

- Redundancy: the social order tolerates redundancy and excessive information exchange;

- Strengthening: the social order matures and creates new routines, tasks and process. The system fosters recovery by promoting the adaptation of routines to the new environment. The social order restarts essential system functions. Learning processes foster the dissemination of acquired experience. The system strengthens itself in order to prevent a new occurrence of the disruptive event. It becomes better prepared and able to protect itself against any consequences. Behaviour supports a return to normal, and the new social order is valued;

- Celebrations are organised to remember the event and maintain cohesion between individuals. 
In March 2011, a major earthquake and a 15-metre tsunami led to the failure of the power supply and cooling systems of three of the six Fukushima Dai Ichi reactors, causing a major nuclear accident.

The accident extended over for five days. During that time, explosions occurred at reactors 1, 2 and 3, and there was a fire at reactor 4 caused by a build-up of hydrogen that resulted in an explosion. The surrounding environment was both devastated and dangerous and roads were impassable. High levels of radiation meant that workers at the plant were completely isolated from emergency services (such as firefighters).

\subsection{Application of the analysis framework}

This sections presents the testimony of Masao Yoshida at official hearings that were held on 22 and 29 July 2011 (Guarnieri et al. 2015). First, the transcription of his testimony is presented, followed by an analysis of specific elements. The following sections present the initial results.

\subsubsection{Phase 1 (restoration of individual balance)}

The events at the nuclear power plant led to the total collapse of points of reference, relations and routine activities. Masao Yoshida's testimony highlights the impact of the consequences of the event both physically and mentally, and underlines the psychological shock leading to the loss of points of reference.

With respect to the first criterion, collapse, the following extract is relevant:

"The shocks became more and more violent. I couldn't stand up any more. Things on shelves fell off, screens went blank (...) All of the false ceilings fell down, documents on shelves were spread all over the floor" (Guarnieri et al. 2015, p. 82)

"At the same time, we learned that the diesel generators didn't work anymore; we said to ourselves that wasn't possible and finally, we said to ourselves that there might have been a tsunami, and this is how, little by little, everybody came to an agreement, arrived at the same conclusion. Right at that moment, we were completely bewildered" (ibid., p. 104).

"Then, to be completely frank, I was devastated. At least personally, I mean. I said to myself that we were facing a terrible situation. But it was no use complaining. Obviously, we were heading towards a major accident and we had to prepare. Here we are; that's what I said to myself. If I had to say what I felt, I would say that my first thought was that something terrible had happened" (ibid., p. 106).

"In these conditions, there were things that we couldn't explain. Things that we couldn't even imagine in our wildest dreams. When we saw indicators, the figures were completely unbelievable. This was what happened to us" (ibid., p. 129). The accident threatened the lives of his team: "I thought that we were going to die" (ibid., p. 216), or "I believed that was the moment when I really hit bottom. I saw us all dead. (...) I had the impression that I wasn't alive any more. I had died" (ibid., p. 266).

"We couldn't see anything" (ibid., p. 97). They could take no action because no information could be passed to the crisis unit: "I heard that we had lost all sources of mains power, that the diesel generators didn't work anymore and we were surprised, we couldn't believe it. At that time, where we were, there were no cameras monitoring the sea level. We were in a situation where the security camera data couldn't reach us. And so we knew nothing about what had happened outside" (ibid., p. 104). "We were all so depressed that we were speechless" (ibid., p.120). "If you can imagine the atmosphere in the room at the time, it was confusion. All sorts of talk about whether some of us were going to survive and others wouldn't" (ibid., p. 93).

With respect to the second criterion, recovery, Yoshida's testimony does not highlight a time that is specifically dedicated to the psychological care of actors. Nevertheless there appears to be consideration for the state of actors and the actions to be undertaken to manage the situation. Yoshida assumes a leadership role:

"Everybody was upset by the earthquake, I clearly remember telling them to regain their composure. I told them that they had to regain their composure, not panic, and that they had to proceed with checks" (ibid., p. 93)

"I asked several times if the RCIC ${ }^{1}$ was working. On the ground, they couldn't see any indicators. Despite that, I asked them to verify them. Then, I only found out later, they had to make enormous sacrifices to do what I wanted. Because to verify the functioning of the RCIC, they had to enter the reactor building. I wasn't careful enough. I knew the check would be difficult" (ibid., p. 200).

The study of the first two hearings does not clearly reveal the existence of the third criterion (diagnosis).

With respect to the fourth criterion, emergence, on 14 March at 11:01 am, when reactor building 1 had already exploded, reactor building 3 exploded. From this moment, the main aim was to regain control over the situation and avoid any escalation. The psychological well-being of agents was not a priority although the Director does show empathy and gratitude to his agents:

\footnotetext{
${ }^{1}$ Reactor Core Isolation Cooling System
} 
"We learned that four people had been hurt, one rather seriously. I heard the news and I knew that nobody had been killed and that all of the services had since been resumed, within the group, which reassured me" (ibid., p. 255). "If it was true and if actually there had been forty deaths, I had decided to commit hara-kiri" (ibid., p. 254).

\subsubsection{Phase 2 (restoration of social order)}

For the criterion exchange the testimony highlights a close interaction between the Director and his agents. He does not allow any criticism of them, which testifies to a strong sense of community: "I would attack anyone who would say such a thing. Really. Please avenge us, on our behalf. We really need it" (Guarnieri et al. 2015, p. 265). This sense of community is seen in how Yoshida perceives his membership of the group in the power plant as different from his membership of other groups: "It was where there was a real gap between those who were actually on the ground, those who were close to the ground, as in the crisis unit, and those who were really far from the ground, for example headquarters" (ibid., p. 138).

With respect to the second criterion, caution and adaptation, this is seen in the fact that Yoshida feels empathy for the teams on the ground: "the staff who were on the ground suffered even more than me" (ibid., p.162). Even if he understands the sacrifices his team made, he must maintain the role of leader and manage the accident. He succeeds in creating a climate of harmony and unity: "I asked them, humbly. That is when I experienced one most great emotions of my life. They wanted all to return to the field, they even pushed each other out of the way. I had to control them. The rush would have been dangerous and counterproductive" (ibid., p. 259).

With respect to the third criterion, creation, the testimony illustrates strong group cohesion and trust during decision-making: collective effort is seen in the strong feeling of identification of individuals with the organisation and its missions. This mechanism is seen in the willingness of the team to return to the field, despite the risk of radiological condition after the explosion of reactor 3, "It was there that most of the men were exposed to radiation at the limit of acceptable values" (ibid., p. 259).

\subsubsection{Phase 3 (restoration of balance with the environment)}

With respect to the criterion increase, the testimony illustrates the spontaneous willingness of workers to carry out activities within the power plant. Yoshida talks about a woman, a member of the prevention group, who did not want to leave after the accident and stayed on in the field to help firefighters: "She worked for a long time in the prevention group, she was a person who had a very strong sense of duty and we couldn't make her leave, I mean she didn't want to leave" (Guarnieri et al. 2015, p. 269). "She ensured that there was gasoline for the fire brigade, she met them, took care of them and the Tokyo fire brigade units that came to help later. She was extremely effective in her work. We talked about her in the newspaper. She was a woman who exceeded the threshold of internal contamination. It is not just about irradiation. She was devoted person, she felt that she had a mission, that's why she worked like that"' (ibid., p. 268).

With respect to redundancy the testimony does not describe a return to normality by adapting the normative framework to a new environment. The identification of solutions did not create a normative framework to resolve problems within a hostile environment:

"By chance, other trucks arrived from outside and, as we had three trucks, we managed to increase the release pressure. All of this was done on the spot, improvised" (ibid., p. 153).

"Personally, the only thing I know is that in the end, nobody did anything for us" (ibid., p. 240). With regard to strengthening the internal resources, they were dysfunctional: "fire hydrants could not supply water, because the fire extinguishing system, which was buried, had melted" (ibid., p. 239)

In other cases, resources were missing and it was necessary to adapt other solutions: "We looked for car batteries, to put them into the control rooms and use them as source of energy" (ibid., p. 115).

The study of the first two hearings provides no material related to the criterion of celebration.

The application of the analysis framework to the testimony of Fukushima Daiichi's Director illustrates the set of criteria. These preliminary results are an initial introduction to an in-depth study of the testimony, which will identify lessons and enrich the resilience activation model.

\section{CONCLUSION}

This article presents the application of an analysis framework for resilience activation. It makes it possible to identify some initial lessons resulting from extreme events.

First, it presents the state-of-the-art regarding models of organisational dynamics in crisis situations, and discusses the concept of resilience activation. Secondly, an analytic framework is developed from the model and it is applied to the testimony of the Director of the Fukushima Dai Ichi nuclear power plant. This analysis 
may help us to understand how resilience is activated in an extreme situation. Our research aims to show how individuals can take decisions and act following this kind of event. Masao Yoshida's testimony teaches us that, despite the beyond-design situation, workers were able to manage the nuclear reactors throughout the critical period.

Three perspectives will structure future research. The first concerns the consolidation of the resilience activation model by taking into account models of the dynamics of resilient systems, and other models that have been developed in the context of human and social sciences of the structure, dynamics and resilience of individuals, groups and organisations. Secondly, the analysis of testimony must be extended to identify any lessons that may serve as a support for learning from experience. Finally, we will investigate resilience activation in more detail. This will involve the detailed study of the interaction between the system and the disruptive event, and how and why the initial actions that are designed to manage the situation are triggered.

This research is financially supported by the French Ministry of Defence, Directorate General of Armaments.

\section{REFERENCES}

Adger, Neil W. 2000. "Social and Ecological Resilience: Are They Related?” Progress in Human Geography 24 (3): 347-64.

Baardwijk, Nicole van, and Patrick Reinmoeller. 2005. "The Link between Diversity and Resilience." MIT Sloan Management Review 46 (4): 61-65.

Béné, Christophe, Rachel Godfrey Wood, Andrew Newsham, and Mark Davies. 2012. Resilience New Utopia or New Tyranny? Reflection about the Potentials and Limits of the Concept of Resilience in Relation to Vulnerability Reduction Programmes. Brighton: IDS.

Bhamra, Ran, Samir Dani, and Kevin Burnard. 2011. "Resilience: The Concept, a Literature Review and Future Directions." International Journal of Production Research 49 (18): 5375-93.

Boyden, Jo, and Gillian Mann. 2005. "Children's Risk, Resilience, and Coping in Extreme Situations." Handbook for Working with Children and Youth: Pathways to Resilience across Cultures and Contexts, 3-26.

Comfort, Louise Kloos. 1999. Shared Risk: Complex Systems in Seismic Response. Amsterdam: Pergamon.

Cutter, Susan L., Lindsey Barnes, Melissa Berry, Christopher Burton, Elijah Evans, Eric Tate, and Jennifer Webb. 2008. "A Place-Based Model for Understanding Community Resilience to Natural Disasters." Global Environmental Change 18 (4): 598 606.

Cyrulnik, Boris, and Claude Seron. 2003. La résilience, ou, Comment renaître de sa souffrance? Paris: Éditions Fabert.

Dalziell, E.P, and S.T McManus. 2004. "Resilience, vulnerability and adaptative capacity: Implications for system performance.” In University of Canterbury - ChristChurch New Zealand. Stoos, Switzerland.

Guarnieri, Franck, and Sébastien Travadel. 2014. "Engineering Thinking in Emergency Situations: A New Nuclear Safety Concept." Bulletin of the Atomic Scientists 70 (6): 79-86.

Guarnieri, Franck, Sébastien Travadel, Christophe Martin, Aurélien Portelli, and Aissame Afrouss. 2015. L'accident de Fukushima Dai Ichi: le récit du directeur de la centrale. Volume I. Paris: Presses des Mines.

Guarnieri, Franck, Sébastien Travadel, Christophe Martin, Aurélien Portelli, Aissame Afrouss, and Eric Przyswa. 2016. L'accident de Fukushima Dai Ichi : le récit du directeur de la centrale. Volume II. Paris: Presse des Mines.

Gunderson, Lance H., and Crawford S. Holling, eds. 2002. Panarchy: Understanding Transformations in Human and Natural Systems. Washington, DC: Island Press.

Holling, Crawford Stanley. 1973. "Resilience and Stability of Ecological Systems." Annual Review of Ecology and Systematics 4: $1-23$.

Hollnagel, Erik, Jean Paries, David Woods, and John Wreathall, eds. 2010. Resilience Engineering in Practice: A Guidebook. Ashgate Studies in Resilience Engineering. Farnham: Ashgate.

Hollnagel, Erik, David D. Woods, and Nancy G. Leveson. 2006. Resilience Engineering: Concepts and Precepts. Aldershot: Ashgate Publishing.

Mileti, Dennis S. 1999. Disasters by Design: A Reassessment of Natural Hazards in the United States. Natural Hazards and Disasters. Washington, D.C: Joseph Henry Press.

Norris, Fran H., Susan P. Stevens, Betty Pfefferbaum, Karen F. Wyche, and Rose L. Pfefferbaum. 2008. "Community Resilience as a Metaphor, Theory, Set of Capacities, and Strategy for Disaster Readiness." American Journal of Community Psychology 41 (12): 127-50.

Paton, D., and Johnston, D. (2001). Disasters and communities: Vulnerability, resilience, and preparedness. Disaster Prevention and Management, 10, 270-277.

Plodinec, John M. 2013. "Definitions of resilience: An analysis." CARRI.

Powley, Edward H. 2009. "Reclaiming Resilience and Safety: Resilience Activation in the Critical Period of Crisis." Human Relations 62 (9): 1289-1326. 
Powley. 2013. "The Process and Mechanisms of Organizational Healing." The Journal of Applied Behavioral Science 49 (1): 42-68.

Powley, Edward H., and Kim S. Cameron. 2008. "Organizational Healing: Lived Virtuousness amidst Organizational Crisis.” In The Virtuous Organization: Insights from Some of the World's Leading Management Thinkers, edited by Charles C. Manz, $21-44$. Singapore: World Scientific.

Powley, Edward H., and Will Powley. 2012. "Building Strength and Resilience: How HR Leaders Enable Healing in Organizations." People and Strategy 35: 42-47.

Richardson, Glenn E. 2002. "The Metatheory of Resilience and Resiliency.” Journal of Clinical Psychology 58 (3): $307-21$

Saint-Arnaud, Sébastien, and Paul Bernard. 2003. "Convergence or Resilience? A Hierarchical Cluster Analysis of the Welfare Regimes in Advanced Countries.” Current Sociology 51 (5): 499-527.

Selye, Hans. 1955. "Stress and Disease.” The Laryngoscope 65 (7): 500-514.

Stallings, Robert A. 2006. "Disaster and the Theory of Social Order." In What Is a Disaster? Perspectives on the Question, edited by Enrico Louis Quarantelli, Digital print, 127-45. London: Routledge.

Travadel, Sébastien, and Franck Guarnieri. 2015. "L'agir En Situation Extrême.” In L'accident de Fukushima Dai Ichi, Le Récit Du Directeur de La Centrale, edited by Franck Guarnieri, Sébastien Travadel, Christophe Martin, Aurélien Portelli, and Aissame Afrouss, 1. L'anéantissement: 283-321. Paris: Presses des Mines.

UNISDR 2009, Terminologie pour la prévention des risques de catastrophe, ISDR.

Walker, Brian, Crawford S. Holling, Stephen R. Carpenter, and Ann Kinzig. 2004. "Resilience, Adaptability and Transformability in Social-ecological Systems." Ecology and Society 9 (2): 5-13.

Wildavsky, Aaron. 1991. Searching for Safety. New Brunswick: Transaction Publ.

Woods D. D., 2006. Essential Characteristics of Resilience, in Hollnagel E., Woods D., Leveson N., Resilience Engineering: Concepts and Precepts, Ashgate. 